\title{
$\beta$-elemene inhibits proliferation of human glioblastoma cells through the activation of glia maturation factor $\beta$ and induces sensitization to cisplatin
}

\author{
TINGZHUN ZHU ${ }^{1}$, YINGHUI XU ${ }^{1}$, BIN DONG ${ }^{1}$, JIANING ZHANG ${ }^{2}$, \\ ZHENQING WEI ${ }^{1}$, YOUSONG XU ${ }^{1}$ and YIQUN YAO ${ }^{1}$ \\ ${ }^{1}$ Department of Neurosurgery, The First Affiliated Hospital of Dalian Medical University, Dalian 116011; \\ ${ }^{2}$ Department of Biochemistry, Dalian Medical University, Dalian 116044, P.R. China
}

Received February 28, 2011; Accepted March 24, 2011

DOI: $10.3892 /$ or.2011.1276

\begin{abstract}
Curcuma wenyujin, strongly inhibits glioblastoma growth. However, the mechanism of $\beta$-elemene antitumor action remains unclear. Glia maturation factor $\beta$ (GMF $\beta$ ) regulates cellular growth, fission, differentiation and apoptosis. It has been reported that overexpression of GMF $\beta$ inhibits the growth of glioblastoma cells and decreases tumor volume. To illustrate the role of GMF $\beta$ in the anti-proliferative effect of $\beta$-elemene in glioblastoma, U87 cells were treated with $\beta$-elemene at various doses and for different periods of time, and levels of phospho-GMF $\beta$ (p-GMF $\beta$ ) and total GMF $\beta$ were determined by immunoprecipitation and Western blot analysis. Upon GMF $\beta$ silencing using RNA interference, the antitumor action of $\beta$-elemene was evaluated in a methyl thiazolyl tetrazolium assay and by semi-quantitative Western blot analysis of MKK3/6 and p-MKK3/6 expression. Finally, chemosensitization to cisplatin by $\beta$-elemene was examined using a cell counting array, and the cell growth inhibitory rate was calculated. The results showed that $\beta$-elemene inhibits U87 cell viability through the activation of the GMF $\beta$ signaling pathway. Conversely, silencing the expression of GMF $\beta$ reversed the antitumor effect of $\beta$-elemene and impaired the phosphorylation of MKK3/6. Furthermore, $\beta$-elemene increased the sensitivity of U87 glioblastoma cells to the chemotherapeutic agent cisplatin. Taken together, these results suggest that activation of the GMF $\beta$ pathway mediates the antitumor effect of $\beta$-elemene in glioblastoma. GMF $\beta$ is a putative molecular target for glioblastoma therapy.
\end{abstract}

Correspondence to: Dr Yinghui Xu, Department of Neurosurgery, The First Affiliated Hospital of Dalian Medical University, No. 222 Zhong Shan Road, Dalian 116011, P.R. China

E-mail: xuyh_dl@yahoo.com.cn

Key words: $\beta$-elemene, glioblastoma, glia maturation factor $\beta$, cisplatin

\section{Introduction}

Glioblastoma is the most common and most malignant type of primary brain tumor, accounting for approximately $52 \%$ of all primary intracranial tumors and $20 \%$ of all brain neoplasms. Glioblastoma is a lethal tumor that is characterized by diffuse infiltration into brain tissue and resistance to conventional anticancer therapies. Despite the use of aggressive surgery, radiation and chemotherapy, it is still difficult to effectively treat efficiently glioblastoma, and the life expectancy of patients with glioblastoma is only $10-14$ months on average after diagnosis (1-5).

Elemene, a novel plant-derived anticancer medicine with low toxicity, is extracted from Curcuma wenyujin and exists as an essential oil mixture of $\beta$-, $\gamma$ - and $\delta$-elemenes (6). As the major active component, $\beta$-elemene (1-methyl1-ethenyl-2,4-isopto-penyl-cyclohexane; molecular formula $\mathrm{C}_{15} \mathrm{H}_{24}$, molecular weight 204.34) has strong anti-proliferative and pro-apoptotic effects on tumors in vitro and in vivo (7-10). Because of its antitumor capability, $\beta$-elemene has been used in the treatment of various types of cancers, such as glioblastoma, breast, liver, laryngeal, leukemia and ovarian (11-14). Our previous findings showed that $\beta$-elemene inhibits the proliferation of different glioblastoma cell lines, induces apoptosis in vitro, and diminishes tumor volume in glioblastoma-bearing nude mice (11,15-17). Furthermore, significant therapeutic effects of $\beta$-elemene were also observed in clinical treatment against glioblastoma (18). However, the anti-glioblastoma mechanism underlying $\beta$-elemene's action remains unclear.

Glia maturation factor $\beta$ (GMF $\beta$, previously known as GMF) is a $17-\mathrm{kDa}$ intracellular regulator of stress-related signal transduction and is expressed predominantly in astrocytes in the brain. GMF $\beta$ is necessary for the growth and maturation of glial cells and neurons $(19,20)$. GMF was found to inhibit the growth of rat $\mathrm{C} 6$ and human HG-1 glioblastoma cells through G0/G1 cell cycle arrest in vitro, decrease tumor volume, and increase the number of cells expressing glial fibrillary acidic protein (GFAP, a marker for normal astrocytes) in the tumors of glioblastoma-bearing mice (21). Mitogen-activated protein kinase (MAPK) pathways, which 
are characterized by MKKK-MKK-MAPK cascades, are important regulators of cellular responses to extracellular stimuli. Mitogen-activated protein kinase kinase-3 (MKK3) and -6 (MKK6) are two kinases that act upstream of $\mathrm{p} 38$ MAPK, and they play important roles in the regulation of cell proliferation, differentiation and apoptosis by phosphorylating the conserved Thr-Gly-Tyr motif in the activation loop of p38 $(22,23)$. We previously found that $\beta$-elemene arrests U87 and C6 glioblastoma cells in G0/G1, inhibiting cell proliferation through the activation of MKK3/6-p38 and the down-regulation of p-ERK1/2, BCL-2 and BCL-X/L $(11,15,16,24)$. It has been reported that overexpression of GMF activates p38 and simultaneously inhibits the activity of ERK $1 / 2$ in C6 cells $(25,26)$. Activation of p38 by GMF $\beta$ sensitizes U87 cells to cisplatin, indicating an important role of the GMF $\beta$-MAPK signaling pathway in the treatment of glioblastoma (27). Therefore, it is essential to illustrate the role of GMF $\beta$ in the anticancer effects of $\beta$-elemene in glioblastoma.

In this study, we investigated the involvement of GMF $\beta$ in the anti-proliferative effects of $\beta$-elemene treatment. We found that $\beta$-elemene inhibited the proliferation of U87 glioblastoma cells through the activation of the GMF $\beta$ signaling pathway. In contrast, silencing the expression of GMF $\beta$ by transfecting siRNA into glioblastoma cells reversed the antitumor effect of $\beta$-elemene and impaired the phosphorylation of MKK3/6. Furthermore, $\beta$-elemene treatment increased the sensitivity of U87 glioblastoma cells to the chemotherapeutic cisplatin. These results suggest that activation of the GMF $\beta$ pathway mediates the anticancer effect of $\beta$-elemene and point to GMF $\beta$ as a putative molecular target for glioblastoma therapy.

\section{Materials and methods}

Reagents, antibodies and cell culture. $\beta$-elemene (98\% purity) was purchased from Jingang Pharmaceutical Co (Dalian, China). Cisplatin was from Hansen Pharmaceutical Co., Ltd. (Lianyungang, China). The antibodies against p-MKK3, p-MKK6, MKK6 and phospho-serine/threonine/tyrosine were from Abcam Inc (UK). The antibodies against MKK3, GMF $\beta$ and GAPDH were from Santa Cruz Biotechnology, Inc (Santa Cruz, CA, USA). An immunoprecipitation kit (Direct IP kit, cat \#26148) was provided by Pierce Chemical Co. (Rockford, IL, USA). Three siRNAs for GMF $\beta$ and a negative control siRNA were from Shanghai GenePharma Co., Ltd (Shanghai, China). A reverse transcription polymerase chain reaction (RT-PCR) kit was purchased from Takara Co., Ltd (Dalian, China). Lipofectamine 2000 transfection reagent was purchased from Invitrogen Corp. (USA). All other reagents, including methylthiazolyl tetrazolium (MTT), were from Sigma-Aldrich (USA). The rat C6 glioblastoma cell line and the human U87 glioblastoma cell line were obtained from Shanghai Cell Bank of Chinese Academy of Sciences, maintained in Dulbecco's modified Eagle's medium supplemented with $10 \%$ fetal calf serum, $50 \mathrm{IU} / \mathrm{ml}$ penicillin and $50 \mathrm{mg} / \mathrm{ml}$ streptomycin, and grown at $37^{\circ} \mathrm{C}$ in a humidified atmosphere with $5 \% \mathrm{CO}_{2}$.

Cell proliferation assay. Cell viability was evaluated using an MTT assay. Cells in exponential growth were cultured in 96 -well culture plates and treated; $20 \mu 1$ of $0.5 \mathrm{mg} / \mathrm{ml}$ MTT was then added to each well, and the mixture was incubated for $4 \mathrm{~h}$ at $37^{\circ} \mathrm{C}$. The culture medium was removed, and the MTT was thoroughly mixed with $200 \mu 1$ of dimethyl sulfoxide to dissolve the formazan crystals. After the 96-well plate was agitated for $10 \mathrm{~min}$ at room temperature, the optical density (OD) of each well was measured at $550 \mathrm{~nm}$ using a spectrophotometric microplate reader (Bio-Tek, USA). Five replicate wells were used for each cell sample.

Western blot assay. Cells were lysed in RIPA buffer [50 $\mathrm{mM}$ Tris- $\mathrm{HCl}$ (pH 7.4), 1.0\% NP-40, 0.25\% Na-deoxycholate, $1 \mathrm{mM}$ EDTA, $150 \mathrm{mM} \mathrm{NaCl}, 1 \mathrm{mM}$ aprotinin, $1 \mathrm{mg} / \mathrm{ml}$ PMSF, $1 \mu \mathrm{g} / \mathrm{ml}$ pepstatin and $1 \mu \mathrm{g} / \mathrm{ml}$ leupeptin]. The total protein concentration in the cellular extracts was measured using the BCA assay kit from Keygen Biotech. Co., Ltd (Nanjing, China). After being separated in 13\% sodium dodecyl sulfate polyacrylamide gels (SDS-PAGE), the proteins were transferred to nitrocellulose filter membranes (Bio-Rad, USA). Membranes were blocked with 5\% BSA in Tris-buffered saline with Tween-20 at room temperature for $2 \mathrm{~h}$ and probed with various primary antibodies at $4^{\circ} \mathrm{C}$ overnight, followed by incubation in horseradish peroxidase-conjugated secondary antibodies at $37^{\circ} \mathrm{C}$ for $2 \mathrm{~h}$. Membranes were exposed to ECL (Amersham, Sweden), and fluorescence was detected by exposing the membrane to X-ray film. The resulting blots were scanned using Image Quant 5.2 software (Amersham).

Immunoprecipitation. Immunoprecipitation was performed using a Direct IP kit from Pierce. This IP kit can be used to chemically cross-link the primary antibody to avoid interference with the antibody light and heavy chain bands during Western blot analysis. According to the manufacturer's instructions, $10 \mu \mathrm{g}$ of primary antibody against human GMF $\beta$ was chemically immobilized onto the coupling resin. Total protein samples were added to the antibody-coupled resin in the spin column and gently rotated at $4{ }^{\circ} \mathrm{C}$ overnight to allow binding of the antigen to the immobilized antibody. The sample was washed with IP lysis/wash buffer and conditioning buffer (provided in the IP kit). GMF $\beta$ protein was completely eluted with elution buffer and collected for further Western blot analysis.

RNA silencing. Cells were plated at a density of $4 \times 10^{5}$ cells per well in 6-well plates or $4 \times 10^{3}$ cells per well in 96-well plates and then cultured for $24 \mathrm{~h}$. siRNA oligonucleotides were transfected into glioblastoma cells with Lipofectamine 2000 according to the manufacturer's instructions. After $24 \mathrm{~h}$, cells were treated with $\beta$-elemene for $24 \mathrm{~h}$. Total protein or RNA was extracted from these cells for further Western blot analysis or RT-PCR analysis. An MTT assay was performed to determine cell viability. All siRNAs were obtained from Shanghai GenePharma Co., Ltd., and the specific sequences used were as follows: human GMF $\beta$ (accession no. NM_004124.2) siRNA-1, sense 5'-GCUUCAUUGUGUAUAGUUATT-3' and anti-sense 5'-UAACUAUACACAAUGAAGCTT-3'; siRNA-2, sense 5'-CAUUGUGUAUAGUUAUAAATT-3' and anti-sense 5'-UUUAUAACUAUACACAAUGTT-3'; siRNA-3, sense 5'-GGUGGGUUGUAAUAAUCAATT-3' and anti-sense 5'-UUGAUUAUUACAACCCACCTT-3'. 

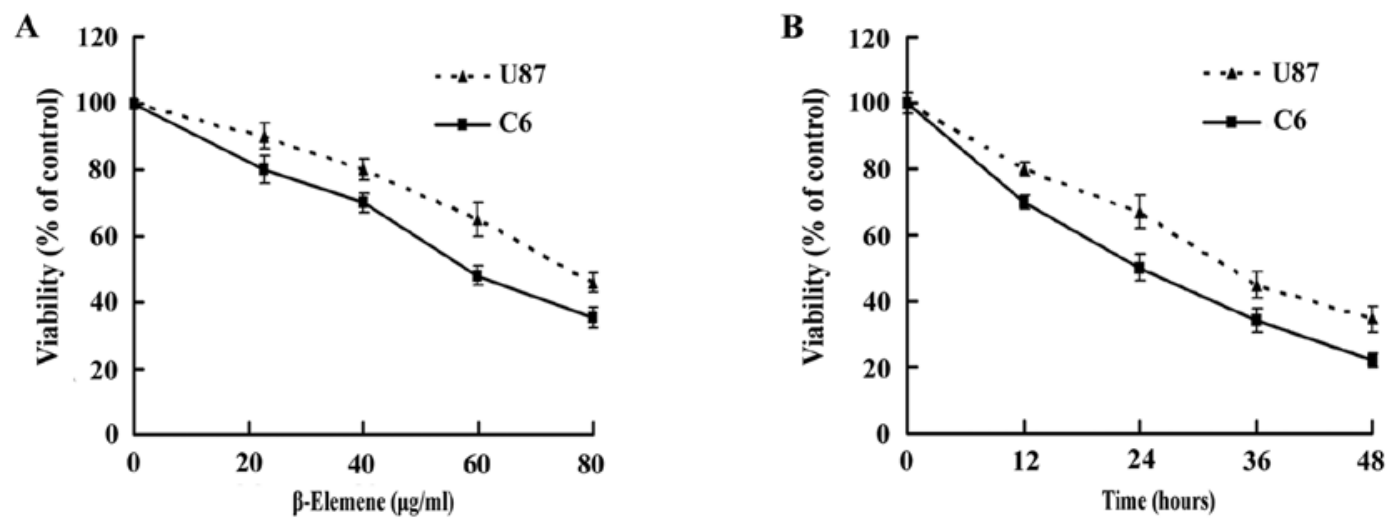

Figure 1. $\beta$-elemene inhibits U87 and C6 cell proliferation dose- and time-dependently. (A) U87 and C6 cells were treated with $\beta$-elemene at various doses $(0,20,40,60$, and $80 \mu \mathrm{g} / \mathrm{ml})$ for $24 \mathrm{~h}$, and cell viability was measured using an MTT assay. (B) U87 and C6 cells were treated with $\beta$-elemene at a concentration of $60 \mu \mathrm{g} / \mathrm{ml}$ for various times $(0,12,24,36$, and $48 \mathrm{~h})$, and an MTT assay was performed to determine cell viability. The viability of cells treated with $\beta$-elemene decreased with increasing drug dose or treatment time. All values are shown as means \pm SD.

Negative control oligonucleotide sequences: sense 5'-UUCUCCGAACGUGUCAGGUTT-3' and anti-sense 5'-ACGUGACACGUUCGGAGAATT-3'. A Blast search of the NCBI database was performed to ensure that the selected GMF $\beta$ siRNA sequences targeted only the GMF $\beta$ gene. The efficiency of RNA interference was determined by Western blot analysis and RT-PCT analysis.

RNA extraction and RT-PCR. Total RNA was isolated from glioblastoma cells by a routine method using TRIzol reagent (Invitrogen, USA). The quality of RNA samples was checked with the DU 640 nucleic acid and protein analyzer (Beckman Coulter, USA). The RT-PCR assay was performed with an RT-PCR kit (Takara) according to the manufacturer's instructions. The specific primers for human GMF $\beta$ and GAPDH were designed using the software Primer Premier 5.0 and synthesized by Takara Co., Ltd. The sequences of the primers were as follows: GMFß: forward, 5'-AGAAACGAACAACGCTGCTA-3' and reverse, 5'-AATCTAACTCCCGACCTT-3'. GAPDH: forward, 5'-AACGGATTTGGTCGTATTG-3' and reverse, 5'-GCTCCTGGAAGATGGTGAT-3'. PCR products were separated on a $1 \%$ agarose gel and stained with ethidium bromide.

Statistical analysis. Values are shown as means \pm standard deviation (SD) of at least three independent experiments. Statistical analysis was performed using the Student's t-test. Differences between groups were identified as statistically significant at $\mathrm{p}<0.05$ and highly significant at $\mathrm{p}<0.01$. Statistical analysis was performed using SPSS software (SPSS, Inc., USA).

\section{Results}

$\beta$-elemene inhibits growth of both human U87 and rat C6 glioblastoma cells in a dose- and time-dependent manner. To evaluate the anticancer effects of $\beta$-elemene, human U87 and rat C6 glioblastoma cells were treated with $\beta$-elemene at different drug doses or for different time periods. Cell viability was determined using an MTT assay. We found that the viability of cells treated with $\beta$-elemene decreased with increasing drug dose (Fig. 1A) and treatment time (Fig. 1B). These results suggest that the proliferation of glioblastoma cells was inhibited by $\beta$-elemene dose- and time-dependently.

$\beta$-elemene increases phosphorylation of GMF $\beta$ in human glioblastoma cells. To investigate the role of GMF $\beta$ in the anti-glioblastoma effect of $\beta$-elemene, we examined the levels of total GMF $\beta$ and p-GMF $\beta$ in $\beta$-elemene-treated U87 cells. Due to the lack of a commercially available primary antibody against $\mathrm{p}-\mathrm{GMF} \beta$, total GMF $\beta$ was isolated from cell extracts by immunoprecipitation with an antibody against GMF $\beta$ and separated by SDS-PAGE in equal protein loading quantity. p-GMF $\beta$ and total GMF $\beta$ levels were then determined respectively by Western blot analysis using antibodies against phospho-serine/threonine/tyrosine and GMF $\beta$. The results of the Western blot analysis were semi-quantitatively estimated using Gel-Pro Analyzer 4.0 software, and the expression levels of p-GMF $\beta$ and total GMF $\beta$ are illustrated in Fig. 2C and D. The results showed that total GMF $\beta$ expression was not affected by treatment with $\beta$-elemene at various concentrations for $24 \mathrm{~h}$ (Fig. 2A and C). However, phosphorylation of GMF $\beta$ increased significantly upon treatment with $60 \mu \mathrm{g} /$ $\mathrm{ml} \beta$-elemene for $24 \mathrm{~h}$ (Fig. 2B and D). The results of this study suggest that $\beta$-elemene treatment increases the levels of $\mathrm{p}-\mathrm{GMF} \beta$ (but not total GMF $\beta)(\mathrm{p}<0.01)$ in concert with its ability to inhibit proliferation of U87 cells.

Treatment with GMF $\beta$ siRNA-1 results in optimal silencing of the expression of GMF $\beta$. Three siRNAs (siRNA-1, -2 and -3) were designed to silence the expression of GMF $\beta$ in U87 glioblastoma cells. These three siRNAs were transfected into U87 cells at $53 \mathrm{nM}$ for $24 \mathrm{~h}$; siRNA-1 was considered the most efficient. To find the optimal interference conditions, various doses of siRNA-1 were transfected into U87 cells for various durations. RT-PCR and Western blot assays were performed to determine the interference efficiency. Our results showed that GMF $\beta$ siRNA-1 silenced the expression 
A Western blot

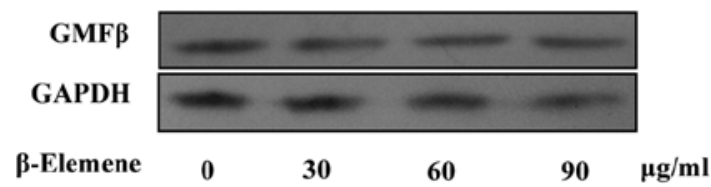

C

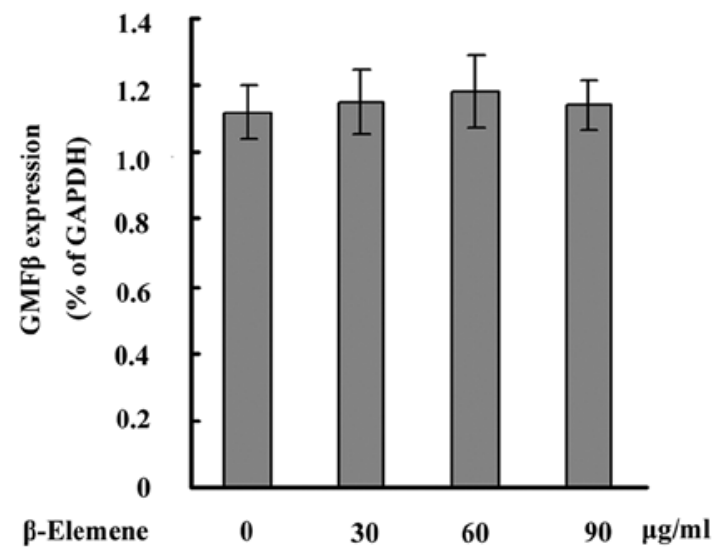

B Immunoprecipitation/Western blot

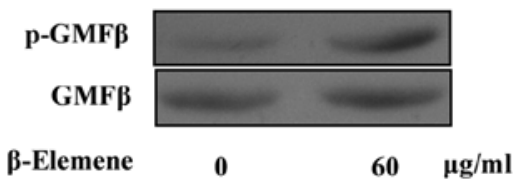

D

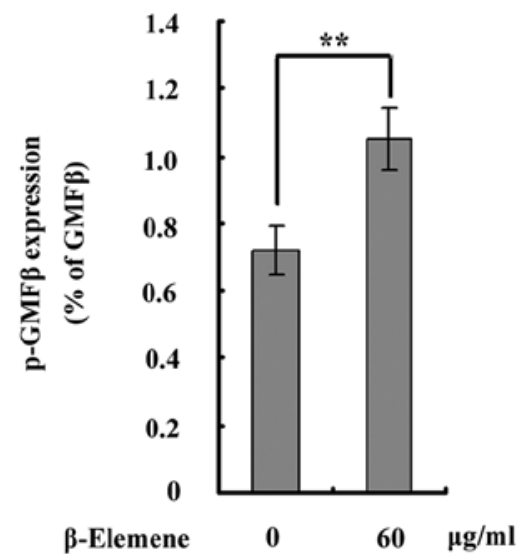

Figure 2. $\beta$-elemene increases the phosphorylation of GMF $\beta$ in human glioblastoma cells. U87 cells were treated with $\beta$-elemene at various drug concentrations for $24 \mathrm{~h}$, and total protein was extracted for Western blot analysis and immunoprecipitation assays. (A) Total GMF $\beta$ expression was detected by Western blot analysis using an antibody against GMF $\beta$ and was not affected by treatment with $\beta$-elemene at different concentrations for $24 \mathrm{~h}$. (B) Total GMF $\beta$ was isolated from cell extracts by immunoprecipitation with an antibody against GMF $\beta$ and separated by SDS-PAGE in equal protein loading quantity. p-GMF $\beta$ and total GMF $\beta$ levels were then determined respectively by Western blot analysis using antibodies against phospho-serine/threonine/tyrosine and GMF $\beta$. (C) The results of A were semi-quantitatively estimated using Gel-Pro Analyzer 4.0 software. (D) The results of B were semi-quantitatively estimated and are illustrated in the histogram. These results indicate that $\beta$-elemene increases the expression of p-GMF $\beta$ (but not total GMF $\beta$ ) ( $\mathrm{p}<0.01$ ) in concert with its ability to inhibit proliferation of U87 cells. Values are shown as means $\pm \mathrm{SD}\left({ }^{* *} \mathrm{p}<0.01\right)$.

\section{A RT-PCR}

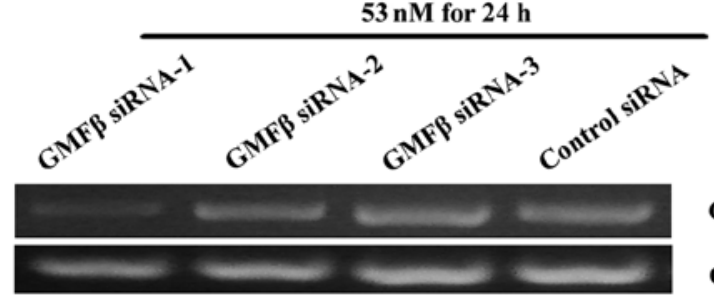

\section{Western blot}

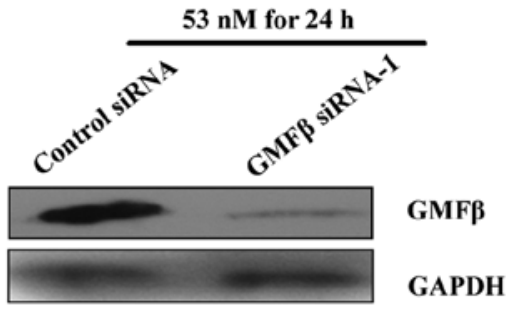

B RT-PCR

GMF $\beta$

GAPDH

$24 \mathrm{~h}$

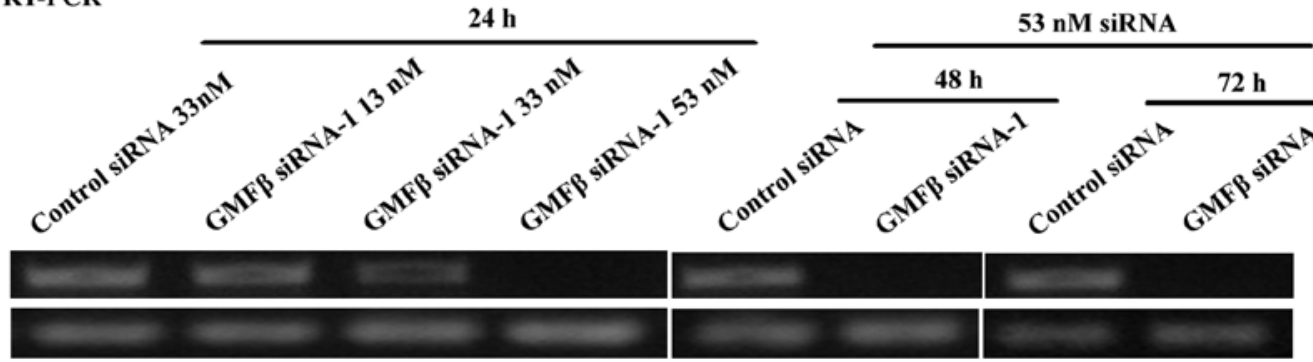

GMF $\beta$

GAPDH

Figure 3. Treatment with GMF $\beta$ siRNA-1 results in optimal silencing of the expression of GMF $\beta$. (A) siRNA-1, -2 and -3 were transfected into U87 cells at $53 \mathrm{nM}$ for $24 \mathrm{~h}$, and the mRNA level of GMF $\beta$ was determined by RT-PCR. The expression of GMF $\beta$ was inhibited more efficiently by siRNA-1 than by siRNA-2 or -3. (B) siRNA-1 was transfected into U87 cells at various doses for different durations. RT-PCR assays were performed to determine the interference efficiency. Transfection with $53 \mathrm{nM}$ siRNA-1 for $24 \mathrm{~h}$ significantly decreased the mRNA expression of GMF $\beta$, and this interference efficiency lasted at least $72 \mathrm{~h}$. (C) The interference efficiency was further verified by Western blot analysis. The protein expression of GMF $\beta$ was efficiently inhibited by treatment with siRNA-1 at $53 \mathrm{nM}$ for $24 \mathrm{~h}$. These results indicated that treatment with $53 \mathrm{nM}$ siRNA-1 for $24 \mathrm{~h}$ was the most effective method to silence the expression of GMF $\beta$. The results are representative of three independent experiments.

of GMF $\beta$ more efficiently than the other siRNAs (Fig. 3A). Transfection with $53 \mathrm{nM}$ siRNA-1 for $24 \mathrm{~h}$ significantly decreased GMF $\beta$ expression, and this interference lasted at least $72 \mathrm{~h}$ (Fig. 3B and C). This study indicates that treatment with $53 \mathrm{nM}$ siRNA-1 for $24 \mathrm{~h}$ was the optimal condition for GMF $\beta$ silencing. 


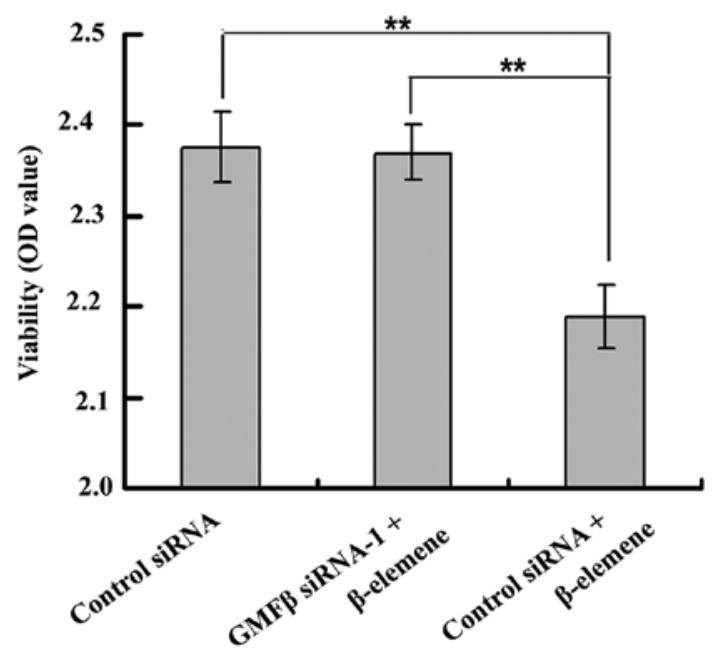

Figure 4. Depletion of GMF $\beta$ by siRNA-1 blocks the anti-proliferative effect of $\beta$-elemene. The expression of GMF $\beta$ was down-regulated by the transfection of siRNA-1 into U87 cells for $24 \mathrm{~h}$. After treatment with $60 \mu \mathrm{g} / \mathrm{ml}$ $\beta$-elemene for $24 \mathrm{~h}$, U87 cell viability was determined using an MTT assay. The results showed that cell viability was higher in the 'GMF $\beta$ siRNA-1 + $\beta$-elemene' group than in the 'Control siRNA $+\beta$-elemene' group $(\mathrm{p}<0.01)$ Values are shown as means $\pm \mathrm{SD}\left({ }^{* *} \mathrm{p}<0.01\right)$.

Down-regulation of GMF $\beta$ by siRNA-1 blocks the antiproliferative effect of $\beta$-elemene in vitro. To confirm a role for GMF $\beta$ activation in the antitumor effect of $\beta$-elemene, GMF $\beta$ expression was silenced by transfection of siRNA-1 into U87 cells for $24 \mathrm{~h}$. After treatment with $\beta$-elemene for $24 \mathrm{~h}$ at $60 \mu \mathrm{g} / \mathrm{ml}$, U87 cell viability was measured in an MTT assay. We found that cell viability in the 'GMF $\beta$ siRNA-1 $+\beta$-elemene' group was higher than that in the 'Control siRNA $+\beta$-elemene' group (Fig. $4, p<0.01$ ). The results of our research suggest that down-regulation of GMF $\beta$ by siRNA-1 blocked the anti-proliferative effect of $\beta$-elemene in vitro.
Depletion of GMF $\beta$ attenuates the stimulation of $M K K 3 / 6$ by $\beta$-elemene. We previously reported that $\beta$-elemene inhibited the proliferation of U87 cells and caused cell-cycle arrest in $\mathrm{G} 0 / \mathrm{G} 1$ via increased phosphorylation of both MKK3/6 and $\mathrm{p} 38$. To investigate the relationship between GMF $\beta$ and the MKK3/6-p38 pathway in the anti-proliferative effect of $\beta$-elemene, U87 cells were treated with $53 \mathrm{nM} \mathrm{GMF} \beta$ siRNA-1 for $24 \mathrm{~h}$ to down-regulate the expression of GMF $\beta$ expression. The cells were treated with $60 \mu \mathrm{g} / \mathrm{ml} \beta$-elemene for $24 \mathrm{~h}$, and the expression levels of $\mathrm{p}-\mathrm{MKK} 3 / 6$ and total MKK3/6 were examined by Western blot analysis with specific antibodies (Fig. 5A). The results were semi-quantitatively estimated using Gel-Pro Analyzer 4.0 software, and the changes in the levels of p-MKK $3 / 6$ and total MKK3/6 are illustrated in Fig. 5B. The results showed that p-MKK3/6 levels were lower in the GMF $\beta$ siRNA-1 group than in the control group $(p<0.01)$. Depletion of GMF $\beta$ attenuated the stimulatory effect of $\beta$-elemene on the MKK3/6 pathway. Taken together, our findings indicate that activation of the GMF $\beta$-MKK3/6-p38 signaling pathway underlay the anti-proliferative effect of $\beta$-elemene in glioblastoma.

Treatment with $\beta$-elemene sensitizes U87 glioblastoma cells to cisplatin-induced cytotoxicity. As previously reported, attenuation of the activity of the GMF $\beta$-p38 pathway mediated the resistance of U87 glioblastoma cells to cisplatininduced cytotoxicity (27). To confirm whether treatment with $\beta$-elemene sensitizes glioblastoma cells to cisplatin, U87 cells were plated at a density of $4 \times 10^{5}$ cells per well in 6-well plates and cultured for $24 \mathrm{~h}$. Cells were organized into the following four groups: control group (untreated, Fig. 6Aa), $\beta$-elemene group (treated with $60 \mu \mathrm{g} / \mathrm{ml} \beta$-elemene for $24 \mathrm{~h}$, Fig. 6Ab), cisplatin group (treated with $20 \mu \mathrm{g} / \mathrm{ml}$ cisplatin for $24 \mathrm{~h}$, Fig. 6Ac) and combination group (treated with $20 \mu \mathrm{g} / \mathrm{ml}$ cisplatin and $60 \mu \mathrm{g} / \mathrm{ml} \beta$-elemene for $24 \mathrm{~h}$, Fig. 6Ad). After treatment with the drugs, cell numbers were measured by cell
A Western blot

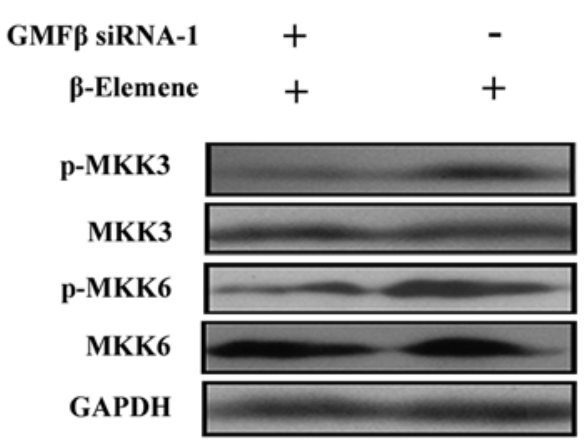

B

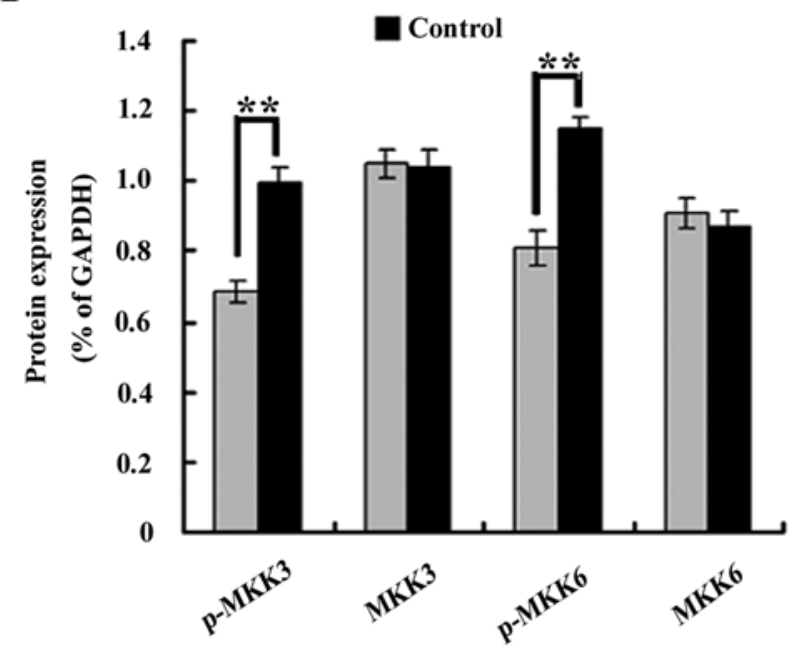

Figure 5. Silencing of the expression of GMF $\beta$ decreased the stimulatory action of $\beta$-elemene on the MKK3/6 pathway. (A) GMF $\beta$ siRNA-1 53 nM was transfected into U87 cells for $24 \mathrm{~h}$ to inhibit GMF $\beta$ expression. U87 cells were treated with $\beta$-elemene at $60 \mu \mathrm{g} / \mathrm{ml}$ for $24 \mathrm{~h}$, and the levels of p-MKK3/6 and total MKK3/6 were detected by Western blot analysis with specific antibodies. (B) Gel-Pro Analyzer 4.0 software was used to semi-quantitatively analyze these bands, and changes in the levels of p-MKK3/6 and total MKK $3 / 6$ are illustrated. p-MKK3/6 levels were lower in the GMF $\beta$ siRNA- 1 group than in the control group $(\mathrm{p}<0.01)$. The results are representative of three independent experiments. Values are shown as means $\pm \operatorname{SD}(* \mathrm{p}<0.01)$. 
A

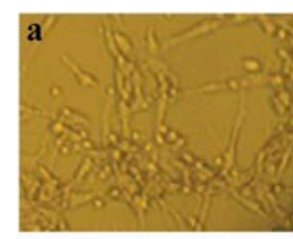

Control group

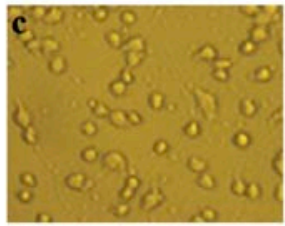

Cisplatin group

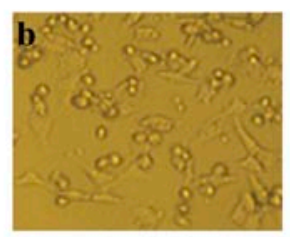

$\beta$-Elemene group

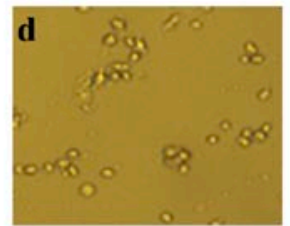

Combination group
B

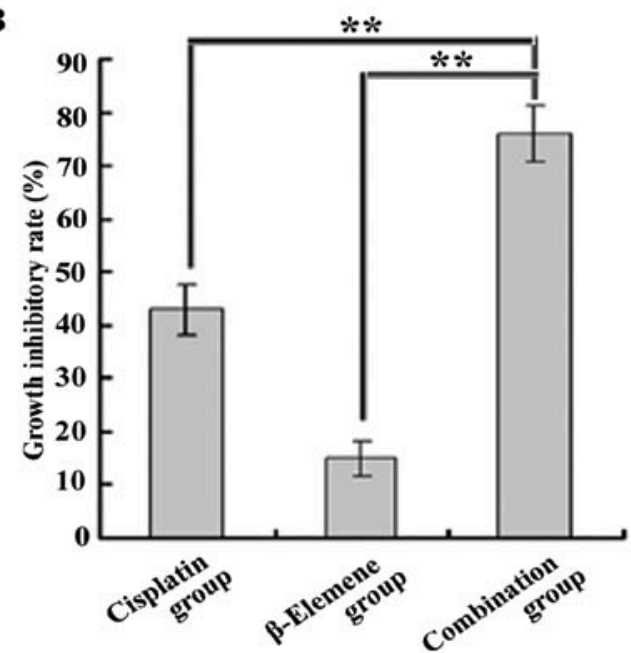

Figure 6. Treatment with $\beta$-elemene increases the sensitivity of U87 cells to cisplatin-induced cytotoxicity. (A) U87 cells were plated at a density of $4 \times 10^{5}$ cells per well in 6-well plates and cultured for $24 \mathrm{~h}$. The following four groups were tested: control group (untreated, a), $\beta$-elemene group (treated with $60 \mu \mathrm{g} / \mathrm{ml} \beta$-elemene for $24 \mathrm{~h}, \mathrm{~b}$ ), cisplatin group (treated with $20 \mu \mathrm{g} / \mathrm{ml}$ cisplatin for $24 \mathrm{~h}$, c) and combination group (treated with $20 \mu \mathrm{g} / \mathrm{ml}$ cisplatin and $60 \mu \mathrm{g} / \mathrm{ml} \beta$-elemene for $24 \mathrm{~h}, \mathrm{~d}$ ). Cell numbers were measured by cell counting. The cell growth inhibitory rate (GIR) was calculated according to the following formula: GIR = [(number of cells in the control group - number of cells in the treated group)/(number of cells in the control group) $\mathrm{x}$ 100\%. (B) The GIRs of the three drug-treated groups are illustrated in the histogram. The results showed that the GIR in the combination group was higher than that in the individual cisplatin $(\mathrm{p}<0.01)$ and $\beta$-elemene $(\mathrm{p}<0.01)$ groups; moreover, the effect of combination treatment was higher than the putative additive effect of cisplatin and $\beta$-elemene treatments. These findings suggest that $\beta$-elemene increases the sensitivity of U87 glioblastoma cells to cisplatin-induced cytotoxicity. Values are shown as means $\pm \mathrm{SD}\left({ }^{* *} \mathrm{p}<0.01\right)$.

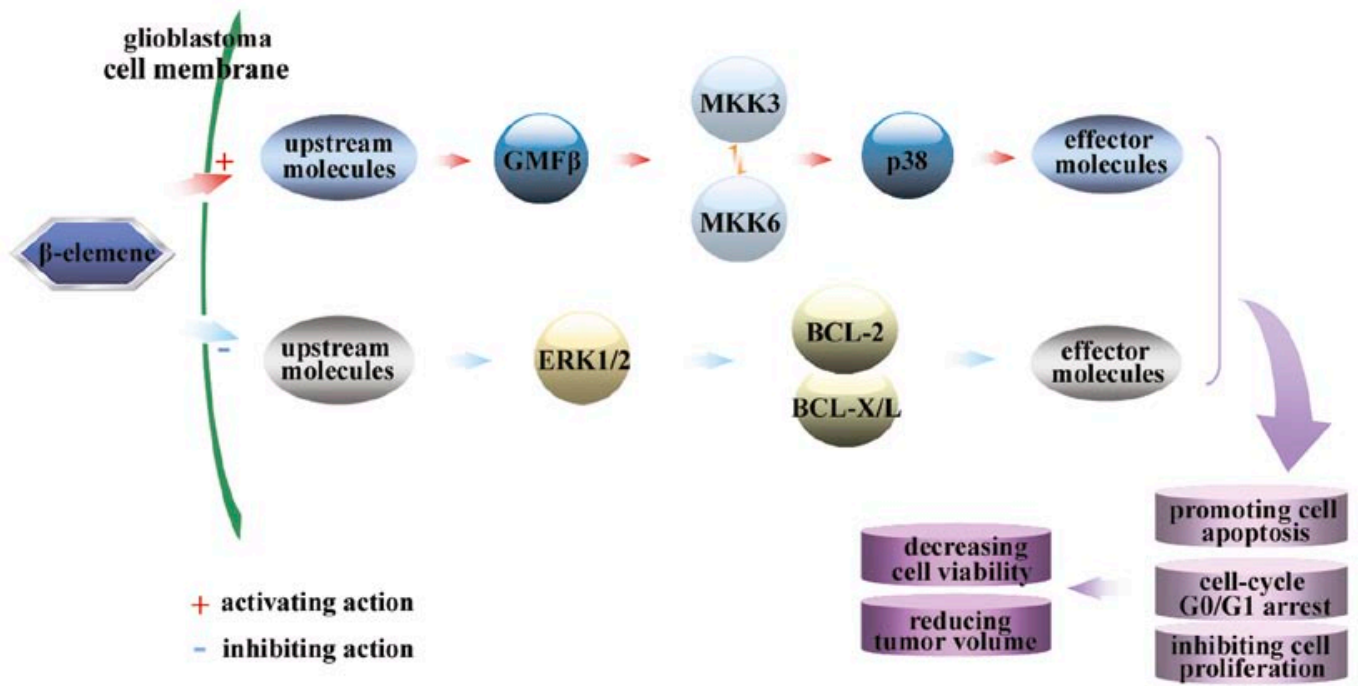

Figure 7. Molecular mechanisms underlying the antitumor effects of $\beta$-elemene in glioblastoma. $\beta$-elemene decreases glioblastoma cell viability and reduces tumor volume by inhibiting cell proliferation, promoting apoptosis and causing cell cycle arrest. Our findings showed that $\beta$-elemene treatment results in these effects via GMF $\beta$-dependent activation of the MKK3/6-p38 pathway and inhibition of the ERK1/2-BCL-2, BCL-X/L pathway. Furthermore, the activation of MKK3 and MKK6 is mutually compensatory in this process.

counting (Beckman). The cell growth inhibitory rate (GIR) was calculated according to the following formula: GIR = [(number of cells in the control group - number of cells in the treated group)/(number of cells in the control group)] $\mathrm{x} 100 \%$. The cell GIRs of the three treated groups are illustrated in Fig. 6B. The results showed that the GIR in the combination group was higher than that in both the cisplatin $(\mathrm{p}<0.01)$ and $\beta$-elemene $(p<0.01)$ groups; moreover, the effect of combination treatment was higher than the putative additive effect of cisplatin and $\beta$-elemene treatments. These findings suggest that $\beta$-elemene increases the sensitivity of U87 glioblastoma cells to cisplatin-induced cytotoxicity.

\section{Discussion}

Glioblastoma is the most common and most deadly form of brain cancer. Despite improvements in therapy, the prognosis for patients with glioblastoma remains dismal. Most 
chemotherapy-based treatments of glioblastoma have proved disappointing because of frequent drug resistance and various severe side effects. The plant-derived, non-cytotoxic, natural product, $\beta$-elemene, has been confirmed as having antitumor activity in vitro and in vivo against various types of tumors such as liver cancer, breast carcinoma, leukemia, laryngeal cancer and ovarian cancer. The anticancer effect of $\beta$-elemene is usually mediated by induction of apoptosis, cell cycle arrest and the inhibition of proliferation; many signaling pathways may be involved in these processes. $\beta$-elemene arrests non-small cell lung cancer cells in the G2-M phase of the cell cycle and induces apoptotic cell death (8). Elemene also inhibits the growth of HEp-2 laryngeal cancer cells and induces apoptosis along with a decrease in the expression of eIFs (4E, 4G), bFGF and VEGF (13). $\beta$-elemene decreases the protein expression of BCL-2, increases cytochrome $\mathrm{c}$ release, and activates PARP and caspases-3, -7, -9 and -10 in prostate cancer cells. In addition, the percentage of prostate cancer cells in apoptosis is increased by $\beta$-elemene treatment dose- and time-dependently (14). Studies have found that $\beta$-elemene showed strong antitumor activity in glioblastoma cell lines from the human and rat, glioblastoma-bearing nude mice and patients with glioblastoma (11,15-18). However, lack of a defined molecular mechanism for the antitumor action of $\beta$-elemene hinders its application in clinical treatment of glioblastoma.

GMF $\beta$ is an intracellular protein that is primarily localized in the mammalian central nervous system and plays an important role in regulating the growth and development of glial cells and neurons. GMF is found to mediate apoptosis in glioblastoma cells as well as the development of inflammation (28-30). Studies have suggested that GMF interacts with ADF/ cofilin to promote the remodeling and/or disassembly of brain cortical actin structures (31). GMF inhibits the proliferation of rat $\mathrm{C} 6$ and human $\mathrm{HG}-1$ glioblastoma cells and restores contact inhibition (21). The overexpression of GMF in N18 neuroblastoma cells increases caspase- 3 activity and causes cytotoxicity and loss of cell viability (32). The overexpression of GMF in astrocytes causes an inflammatory response through the activation of the GMF-p38/NF- $\mathrm{BB} / \mathrm{GM}-\mathrm{CSF} / \mathrm{TNF}-\alpha$, IL-1 $\beta$ and IL-6 signaling pathways (19). p38, ERK1/2 and JNK are the centers of three major MAPK pathways (12-16). ERK1/2 is an upstream activator of the proto-oncogene BCL-2 and BCL-X/L and is thought to be linked to cell proliferation and tumor development (33). MKK3 and MKK6 are two kinases that act upstream of p38 MAPK. After activation by MKK kinases such as TAK1, ASK1 and MLKs $(21,22)$, MKK3/6 can affect the activity of MSK1, IL-12, NF- $\mathrm{B}, \mathrm{MCL}-1$ and p53 by the phosphorylation of p38 MAPK (34-38). MKK3/6-p38 activation negatively regulates proliferation via attenuation of the promoter activity of cyclin D1, increasing the percentage of cells in G0/G1 phase of the cell cycle, while MKK1-ERK1/2 activation has the opposite effect (39). MKK3/6 also mediates the antitumor effects of various drugs, such as isoflavone derivatives, sodium butyrate, TNF- $\alpha$ and gemcitabine (40-43). Studies have shown that overexpression of GMF can simultaneously activate p38 and inhibit the activity of ERK1/2 $(25,26)$. GMF can be phosphorylated at threonine 26 and serine 82 by PKA, at serine 71 by PKC, at threonine 26 by 900 ribosomal S6 kinase and at serine 52 by casein kinase II. The phosphorylation of various sites on GMF may explain its opposing effects on p38 and ERK1/2 (44). Our previous research found that $\beta$-elemene arrested C6 and U87 glioblastoma cells in the G0/G1 phase of the cell cycle and inhibited cell proliferation by activating MKK3/6-p38 and decreasing the expression of p-ERK $1 / 2, \mathrm{BCL}-2$ and BCL-X/L; the JNK pathway was not involved in this effect $(11,16,24)$. The present study revealed that $\beta$-elemene inhibits the proliferation of glioblastoma cells through the activation of the GMF $\beta$ signaling pathway. Furthermore, a down-regulation of GMF $\beta$ expression by RNA interference decreased the phosphorylation of MKK3 and MKK6 and reversed the anti-glioblastoma effect of $\beta$-elemene. In combination with our previous findings, these results suggest that $\beta$-elemene inhibits the proliferation of human glioblastoma cells, induces apoptosis and causes cell cycle arrest via a GMF $\beta$-dependent activation of the MKK3/6-p38 pathway as well as an inhibition of the ERK1/2-BCL-2, BCL-X/L pathway. Furthermore, the activation of MKK3 and MKK6 is mutually compensatory in this process (Fig. 7).

Cisplatin is a highly efficient chemotherapeutic that is used to clinically treat many malignant solid tumors. However, U87 glioblastoma cells are quite resistant to cisplatin since signaling through the GMF $\beta$-p38 pathway is attenuated in these cells (27). Therefore, we examined the sensitivity of $\beta$-elemene-treated U87 cells to cisplatin-induced cytotoxicity. The results of the present study indicate that $\beta$-elemene and cisplatin have synergistic inhibitory effects on cell growth. We suggest that the enhancement of cisplatin's efficacy by $\beta$-elemene is related to the activation of the GMF $\beta$-MKK3/6-p38 signaling pathway. In addition, the chemosensitizing effect of $\beta$-elemene has been confirmed in prostate carcinoma cells and human non-small cell lung cancer cells and has been correlated with activation of many members of the caspase family and suppression of the BCL-2, BCL-X/L or IAP proto-oncogene $(45,46)$. Similarly, the synergistic anticancer effect of $\beta$-elemene and cisplatin was observed in human laryngeal carcinoma-bearing nude mice and in ovarian carcinoma cells $(9,47)$. As a promising chemosensitizer or adjuvant, $\beta$-elemene is worthy of further study, which may lead to the development of a therapeutic regimen combining $\beta$-elemene with cisplatin or other chemotherapeutics in the treatment of malignant tumors.

In conclusion, we propose that activation of GMF $\beta$, an upstream activator of MKK3/6, mediates the antitumor effects of $\beta$-elemene. GMF $\beta$ is a putative target for molecular therapy and combination chemotherapy in glioblastoma.

\section{Acknowledgements}

This research was supported by the National Natural Science Foundation of China (no. 30740027/30471778). We also thank all of our colleagues in our research group for their generous support.

\section{References}

1. Louis DN, Ohgaki H, Wiestler OD, Cavenee WK, Burger PC, Jouvet A, Scheithauer BW and Kleihues P: The 2007 WHO classification of tumours of the central nervous system. Acta Neuropathol 114: 97-109, 2007. 
2. Wen PY and Kesari S: Malignant gliomas in adults. N Engl J Med 359: 492-507, 2008.

3. Kang TY, Jin T, Elinzano H and Peereboom D: Irinotecan and bevacizumab in progressive primary brain tumors, an evaluation of efficacy and safety. J Neurooncol 89: 113-118, 2008.

4. Clarke J, Butowski N and Chang S: Recent advances in therapy for glioblastoma. Arch Neurol 67: 279-283, 2010.

5. Van Meir EG, Hadjipanayis CG, Norden AD, Shu HK, Wen PY and Olson JJ: Exciting new advances in neuro-oncology: the avenue to a cure for malignant glioma. CA Cancer J Clin 60: 166-193, 2010

6. Chen SL, You J and Wang GJ: Supercritical fluid extraction of beta-elemene under lower pressure. Se Pu 19: 179-181, 2001.

7. Wang K, Li Z, Chen Y and Su C: The pharmacokinetics of a novel antitumor agent, beta-elemene, in Sprague-Dawley rats. Biopharm Drug Dispos 26: 301-307, 2005.

8. Wang G, Li X, Huang F, Zhao J, Ding H, Cunningham C, Coad JE, Flynn DC, Reed E and Li QQ: Antitumor effect of beta-elemene in non-small-cell lung cancer cells is mediated via induction of cell cycle arrest and apoptotic cell death. Cell Mol Life Sci 62: 881-893, 2005

9. Li X, Wang G, Zhao J, Ding H, Cunningham C, Chen F, Flynn DC, Reed E and Li QQ: Antiproliferative effect of betaelemene in chemoresistant ovarian carcinoma cells is mediated through arrest of the cell cycle at the G2-M phase. Cell Mol Life Sci 62: 894-904, 2005.

10. Xu L, Tao S, Wang X, Yu Z, Wang M, Chen D, Jing Y and Dong J: The synthesis and anti-proliferative effects of betaelemene derivatives with mTOR inhibition activity. Bioorg Med Chem 14: 5351-5356, 2006.

11. Yao YQ, Ding X, Jia YC, Huang CX, Wang YZ and Xu YH: Anti-tumor effect of beta-elemene in glioblastoma cells depends on p38 MAPK activation. Cancer Lett 264: 127-134, 2008.

12. Peng X, Zhao Y, Liang X, Wu L, Cui S, Guo A and Wang W: Assessing the quality of RCTs on the effect of beta-elemene, one ingredient of a Chinese herb, against malignant tumors. Contemp Clin Trials 27: 70-82, 2006.

13. Tao L, Zhou L, Zheng L and Yao M: Elemene displays anticancer ability on laryngeal cancer cells in vitro and in vivo. Cancer Chemother Pharmacol 58: 24-34, 2006.

14. Li QQ, Wang G, Huang F, Banda M and Reed E: Antineoplastic effect of beta-elemene on prostate cancer cells and other types of solid tumour cells. J Pharm Pharmacol 62: 1018-1027, 2010

15. Zhu T, Zhao Y, Zhang J, Li L, Zou L, Yao Y and Xu Y: $\beta$-elemene inhibits proliferation of human glioblastoma cells and causes cell-cycle G0/G1 arrest via mutually compensatory activation of MKK3 and MKK6. Int J Oncol 38: 419-426, 2011.

16. Xu YH, Dong B, Luo QZ, Zhou HY, Jia YC, Yang YF and Wang YZ: Influence of elemene on the expression of Bcl-2 family genes in rat C6 glioma cells. Zhonghua Yi Xue Za Zhi 85: 1700-1703, 2005.

17. Yao YQ, Xu YH, Lu J, Zhou HY and Wang YZ: Effect of p38 MAPK on elemene-induced cell cycle arrest in C6 glioblastoma cells. Zhonghua Yi Xue Za Zhi 88: 56-58, 2008.

18. Tan P, Zhong W and Cai W: Clinical study on treatment of 40 cases of malignant brain tumor by elemene emulsion injection. Zhongguo Zhong Xi Yi Jie He Za Zhi 20: 645-648, 2000.

19. Zaheer A, Zaheer S, Sahu SK, Knight S, Khosravi H, Mathur SN and Lim R: A novel role of glia maturation factor: induction of granulocyte-macrophage colony-stimulating factor and proinflammatory cytokines. J Neurochem 101: 364-376, 2007.

20. Kaimori JY, Takenaka M, Nakajima H, Hamano T, Horio M, Sugaya T, Ito T, Hori M, Okubo K and Imai E: Induction of glia maturation factor-beta in proximal tubular cells leads to vulnerability to oxidative injury through the p38 pathway and changes in antioxidant enzyme activities. J Biol Chem 278: 33519-33527, 2003.

21. Lim R, Hicklin DJ, Ryken TC, Han XM, Liu KN, Miller JF and Baggenstoss BA: Suppression of glioma growth in vitro and in vivo by glia maturation factor. Cancer Res 46: 5241-5247, 1986.

22. Kang YJ, Seit-Nebi A, Davis RJ and Han J: Multiple activation mechanisms of p38alpha mitogen-activated protein kinase. J Biol Chem 281: 26225-26234, 2006

23. Dérijard B, Raingeaud J, Barrett T, Wu IH, Han J, Ulevitch RJ and Davis RJ: Independent human MAP-kinase signal transduction pathways defined by MEK and MKK isoforms. Science 267: 682-685, 1995

24. Yao YQ, Xu YH, Zhou HY, Cui CZ and Wang YZ: Role of ERK in the inhibitory effects of elemene on the proliferation of rat C6 glioblastoma cells. Tumor 27: 777-779, 2007.
25. Zaheer A and Lim R: In vitro inhibition of MAP kinase (ERK1/ ERK2) activity by phosphorylated glia maturation factor (GMF). Biochemistry 35: 6283-6288, 1996.

26. Lim R and Zaheer A: In vitro enhancement of p38 mitogen-activated protein kinase activity by phosphorylated glia maturation factor. J Biol Chem 271: 22953-22956, 1996.

27. Baldwin RM, Garratt-Lalonde M, Parolin DA, Krzyzanowski PM, Andrade MA and Lorimer IA: Protection of glioblastoma cells from cisplatin cytotoxicity via protein kinase Ciotamediated attenuation of p38 MAP kinase signaling. Oncogene 25: 2909-2919, 2006.

28. Zaheer A, Zaheer S, Thangavel R, Wu Y, Sahu SK and Yang B: Glia maturation factor modulates beta-amyloid-induced glial activation, inflammatory cytokine/chemokine production and neuronal damage. Brain Res 1208: 192-203, 2008.

29. Zaheer A, Zaheer S, Sahu SK, Yang B and Lim R: Reduced severity of experimental autoimmune encephalomyelitis in GMF-deficient mice. Neurochem Res 32: 39-47, 2007.

30. Zaheer S, Wu Y, Bassett J, Yang B and Zaheer A: Glia maturation factor regulation of STAT expression: a novel mechanism in experimental autoimmune encephalomyelitis. Neurochem Res 32: 2123-2131, 2007

31. Gandhi M, Smith BA, Bovellan M, Paavilainen V, DaughertyClarke K, Gelles J, Lappalainen P and Goode BL: GMF is a cofilin homolog that binds Arp2/3 complex to stimulate filament debranching and inhibit actin nucleation. Curr Biol 20: 861-867, 2010.

32. Zaheer A, Knight S, Zaheer A, Ahrens M, Sahu SK and Yang B: Glia maturation factor overexpression in neuroblastoma cells activates glycogen synthase kinase-3beta and caspase-3. Brain Res 1190: 206-214, 2008.

33. Lawrence MC, Jivan A, Shao C, Duan L, Goad D, Zaganjor E, Osborne J, McGlynn K, Stippec S, Earnest S, Chen W and Cobb MH: The roles of MAPKs in disease. Cell Res 8: 436-442, 2008.

34. Lee HY, Crawley S, Hokari R, Kwon S and Kim YS: Bile acid regulates MUC2 transcription in colon cancer cells via positive EGFR/PKC/Ras/ERK/CREB, PI3K/Akt/IkappaB/NF-kappaB and $\mathrm{p} 38 / \mathrm{MSK} 1 / \mathrm{CREB}$ pathways and negative JNK/c-Jun/AP-1 pathway. Int J Oncol 36: 941-953, 2010.

35. Yang Z, Zhang X, Darrah PA and Mosser DM: The regulation of Th1 responses by the p38 MAPK. J Immunol 185: 6205-6213, 2010.

36. Kumar V, Behera R, Lohite K, Karnik S and Kundu GC: p38 kinase is crucial for osteopontin-induced furin expression that supports cervical cancer progression. Cancer Res 70: 10381-10391, 2010.

37. Son JK, Varadarajan S and Bratton SB: TRAIL-activated stress kinases suppress apoptosis through transcriptional upregulation of MCL-1. Cell Death Differ 17: 1288-1301, 2010.

38. Shin JS, Woo SH, Lee HC, Hong SW, Yoo DH, Hong SI, Lee WJ, Lee MS, Jin YW, An S, Jin DH and Park IC: Low doses of ionizing radiation suppress doxorubicin-induced senescencelike phenotypes by activation of ERK1/2 and suppression of p38 kinase in MCF7 human breast cancer cells. Int J Oncol 36: $1445-1452,2010$.

39. Terada Y, Nakashima O, Inoshita S, Kuwahara M, Sasaki S and Marumo F: Mitogen-activated protein kinase cascade and transcription factors: the opposite role of MKK3/6-p38K and MKK1-MAPK. Nephrol Dial Transplant 14 (Suppl 1): 45-47, 1999.

40. Chen JT, Fong YC, Li TM, Liu JF, Hsu CW, Chang CS and Tang CH: DDTD, an isoflavone derivative, induces cell apoptosis through the reactive oxygen species/apoptosis signal-regulating kinase 1 pathway in human osteosarcoma cells. Eur J Pharmacol 597: 19-26, 2008

41. Cho SD, Ahn NS, Jung JW, Yang SR, Park JS, Lee YS, Jo EH, Hwang JW, Lii J and Kang KS: Critical role of the c-JunNH2terminal kinase and p38 mitogen-activated protein kinase pathways on sodium butyrate-induced apoptosis in DU145 human prostate cancer cells. Eur J Cancer Prev 15: 57-63, 2006.

42. Liu AH, Deng P and Jiang Y: The TNF-alpha-induced apoptosis of LA795 cells is mediated by MAP kinase kinase 6 . Zhonghua Jie He He Hu Xi Za Zhi 26: 88-92, 2003.

43. Habiro A, Tanno S, Koizumi K, Izawa T, Nakano Y, Osanai M, Mizukami Y, Okumura T and Kohgo Y: Involvement of p38 mitogen-activated protein kinase in gemcitabine-induced apoptosis in human pancreatic cancer cells. Biochem Biophys Res Commun 316: 71-77, 2004 
44. Zaheer A and Lim R: Protein kinase A (PKA)- and protein kinase C-phosphorylated glia maturation factor promotes the catalytic activity of PKA. J Biol Chem 272: 5183-5186, 1997.

45. Li QQ, Wang G, Reed E, Huang L and Cuff CF: Evaluation of cisplatin in combination with beta-elemene as a regimen for prostate cancer chemotherapy. Basic Clin Pharmacol Toxicol 107: 868-876, 2010.
46. Li QQ, Wang G, Zhang M, Cuff CF, Huang L and Reed E: betaElemene, a novel plant-derived antineoplastic agent, increases cisplatin chemosensitivity of lung tumor cells by triggering apoptosis. Oncol Rep 22: 161-170, 2009.

47. Tao L, Zhou L, Zheng LY and Yao M: Inhibition of eIF families expression and angiogenesis for human laryngeal carcinoma by elemene administration. Zhonghua Er Bi Yan Hou Tou Jing Wai Ke Za Zhi 40: 840-845, 2005. 